\title{
Overdose of Venlafaxine with Mild Outcome
}

\author{
Matthias Fischer, Stefan Unterecker, Bruno Pfuhlmann
}

Department of Psychiatry, Psychosomatics and Psychotherapy, University of Wuerzburg, Wuerzburg, Germany. Email: Fischer_m2@klinik.uni-wuerzburg.de

Received July $30^{\text {th }}$, 2012; revised August 24 $4^{\text {th }}$, 2012; accepted September $10^{\text {th }}, 2012$

\begin{abstract}
The antidepressant venlafaxine in overdose can lead to serotonin syndrome, seizures, QTc interval prolongation and can increase the risk of cardiac arrhythmias. It has been reported to be more toxic in overdose than other new antidepressants. We report a case of venlafaxine intoxication with a venlafaxine/O-desmethylvenlafaxine serum level of $2861 / 2670 \mathrm{ng} / \mathrm{mL} 22 \mathrm{~h}$ after ingestion. This is one of the so far highest survived venlafaxin serum levels. In contrast to other reported survived venlafaxin overdoses with high serum levels no clinical signs of intoxication were observed in our case. So venlafaxine overdose not necessarily leads to life-threatening signs of intoxication.
\end{abstract}

Keywords: Venlafaxine; Intoxication; Overdose; Drug Monitoring

\section{Introduction}

The widely used antidepressant venlafaxine (VEN) inhibits the reuptake of serotonin, noradrenaline and dopamine [1]. The P450 enzyme CYP2D6 metabolizes it to O-desmethylvenlafaxine (ODV). In comparison with other new antidepressants, venlafaxine has a rather high fatal toxicity index. It caused 12.7 deaths per million prescriptions in contrast to 1.9 for selective serotonin reuptake inhibitors (SSRIs), and resembles tricyclic antidepressants (TCAs) in this respect [2]. The mortality per selfpoisoning index for venlafaxine was lower than for TCAs, but higher than for SSRIs [3].

\section{Case Report}

We report the case of a 41 years old female patient with major depressive disorder and social phobia, who ingested $3075 \mathrm{mg}$ non-retarded venlafaxine tablets (2250 $\mathrm{mg}$ ) in suicidal intention. In addition she took $207.5 \mathrm{mg}$ tablets $(150 \mathrm{mg})$ of zopiclone, a hypnotic drug with similarities to benzodiazepines. She had been suffering from nausea, dizziness, anxiety, diarrhea, tingling sensation, burning sensation of the skin, unrest and insomnia over several months. The patient had a history of depressive episodes and anxiety symptoms like panic attacks and social phobia for about four years and suffered from mild hypothyreoidism. Approximately 15 hours after ingestion of the drugs she was admitted to an intensive care unit. Besides monitoring of vital parameters including ECG and elevation of blood $\mathrm{pH}$ no further measures were taken. Clinical signs of intoxication were never observed. Psychopathologically, the patient was orientated, had a slightly reduced mnestic and cognitive function, a depressed mood and was a little agitated. All of these findings can be explained by the depressive syndrome. The immediate ECG recording (15 hours after ingestion of the overdose) in the intensive care unit showed a normal QTc interval (Bazett) of 419 ms and a normal QRS interval of $82 \mathrm{~ms}$. Heart rate was elevated with $117 / \mathrm{min}$. Respiration frequency was 24/min. Two days later, QTc interval was 426 ms with a heart rate of $78 / \mathrm{min}$. Blood pressure in the intensive care unit was initially within normal limits with 130/80 mmHg. Creatine kinase (CK) as a possible sign for serotonergic syndrome was normal with $56 \mathrm{U} / \mathrm{l}$. Leukocytes were slightly elevated with 13 $700 / \mu l$. Other common laboratory findings including sodium, potassium, calcium and magnesium were within normal range. In an MRI recording of the brain, minimal signs of increased signal intensities were observed in parietal periventricular white matter. A subsequent cerebrospinal fluid diagnostic test showed normal results. After the patient was transferred to the psychiatric clinic (22 hours post-ingestion) serum levels of VEN and ODV were determined. They were $2861 \mathrm{ng} / \mathrm{mL}$ for VEN and $2670 \mathrm{ng} / \mathrm{mL}$ for ODV. Sixty-five hours later, drug levels were $19 \mathrm{ng} / \mathrm{mL}$ and $88 \mathrm{ng} / \mathrm{mL}$, respectively. Drug levels were determined with isocratic reversed-phase high performance liquid chromatography (HPLC) with fluorescence detection.

\section{Discussion}

Venlafaxine overdose can cause seizures, QTc interval prolongation and increase the risk of cardiac arrhythmias, 
diaphoresis, sedation, hypertension, hypotension and hyponatremia [2,4-6]. Tachycardia and prolonged QTc after overdose of venlafaxine seem to be dose dependent [2]. In a comparative study, venlafaxine intoxication led to serotonin syndrome features like significantly higher pulse rates, increased agitation and tremor more frequently than citalopram, mirtazapine and nefazadone [4]. The median fatal post-mortem concentration of VEN/ODV in a study by Launiainen [7] was 6070/1110 ng/mL.

Table 1 gives an overview on reported fatal (with venlafaxine playing a significant role in the cause of death) and non-fatal VEN blood levels (no information whether retarded or non-retarded VEN available). However, post-mortem blood levels might be artificially high due to redistribution [12]. The recommended therapeutic level ranges from 100 to $400 \mathrm{ng} / \mathrm{mL}$ [16]. Taking into account that the expected peak blood level is reached 2 3 hours after ingestion the VEN/ODV level of 2861/2670 $\mathrm{ng} / \mathrm{mL}, 22$ hours post ingestion is one of the highest survived levels reported so far. According to the calculated elimination half-life of non-retarded venlafaxine of 9 hours, in our patient the peak blood level of VEN after

Table 1. Reported post-mortem (pm) or survived venlafaxine blood levels.

\begin{tabular}{|c|c|c|c|}
\hline $\begin{array}{l}\text { VEN/ODV-level } \\
\text { (ng/mL) }\end{array}$ & Survived/pm & $\mathrm{mdi}^{\mathrm{a}}$ & Reference \\
\hline $6600 / 31,000$ & $\mathrm{pm}$ & + & Levine et al. 1996 [8] \\
\hline $84,000 / 15,000$ & pm & + & Levine et al. 1996 \\
\hline $44,000 / 50,000$ & $\mathrm{pm}$ & - & Levine et al. 1996 \\
\hline $17,000 / ?$ & $\mathrm{pm}$ & + & Parson et al. 1996 [9] \\
\hline $65,000 /$ & $\mathrm{pm}$ & - & Parson et al. 1996 \\
\hline $76,000 / ?$ & $\mathrm{pm}$ & $?$ & Budd et al. 1997 [10] \\
\hline $13,000 / ?$ & $\mathrm{pm}$ & $?$ & Budd et al. 1997 \\
\hline $6520 / 6900$ & $\mathrm{pm}$ & - & Long et al. 1997 [11] \\
\hline $89,670 /$ & $\mathrm{pm}$ & - & Long et al. 1997 \\
\hline $53,000 / ?$ & $\mathrm{pm}$ & - & Jaffe et al. 1999 [12] \\
\hline $78,000 / ?$ & $\mathrm{pm}$ & - & Jaffe et al. 1999 \\
\hline $1800 /<0.05$ & $\mathrm{pm}$ & + & Goeringer et al. 2001 [13] \\
\hline 7200/700 & $\mathrm{pm}$ & + & Goeringer et al. 2001 \\
\hline $31,000 /$ & $\mathrm{pm}$ & + & Goeringer et al. 2001 \\
\hline $6240 / ?$ & survived & + & Fantaskey et al. 1995 [14] \\
\hline 2350/? & survived & $?$ & Fantaskey et al. 1995 \\
\hline $6100 / 1800^{\mathrm{b}}$ & survived & + & Fantaskey et al. 1995 \\
\hline $12,000 / 1200^{c}$ & survived & - & Kokan et al. 1996 [15] \\
\hline $14,490 / 5135^{\mathrm{d}}$ & survived & - & Blythe et al. 1999 [5] \\
\hline
\end{tabular}

${ }^{\mathrm{a}}$ mdi = multiple drug intoxication; ${ }^{\mathrm{b}}$ severe central nervous system depression requiring intubation; ${ }^{\mathrm{b}}$ and ${ }^{\mathrm{c}} 4 \mathrm{~h}$ post ingestion; ${ }^{\mathrm{d}} 6 \mathrm{~h}$ post ingestion. this intoxication should have been around 12,000 ng/mL. Our case varies in its clinical course from other cases with survived high VEN serum levels. Unfortunately the CYP2D6 genotype of our patient is unknown. One case has been reported with a similar VEN blood level around $3000 \mathrm{ng} / \mathrm{mL}$ at 20 hours after ingestion and 14,490 $\mathrm{ng} / \mathrm{mL}$ about six hours after ingestion as the maximum concentration [5]. The patient had prolonged QRS and QTc intervals (ECG six hours after suicide attempt) and was intubated following several seizures. A second patient with a similar high survived serum level showed QRS and QTc prolongation, seizures, life-threatening hypotension and increased heart rate [15]. Patients with even lower survived serum levels showed convulsions and QTc prolongation $(6240 \mathrm{ng} / \mathrm{mL})$ or were intubated due to severe central nervous system depression [14] $(6100 \mathrm{ng} / \mathrm{mL})$. In contrast none of these signs of intoxication like prolongation of QTc interval as a risk factor for life-threatening torsade-de-pointes arrhythmias, increased blood pressure, seizures, or serotonergic syndrome was observed in our patient. She could leave the intensive care unit after a few hours. So high VEN serum levels due to overdose not necessarily lead to life-threatening signs of intoxication.

\section{REFERENCES}

[1] S. M. Holliday and P. Benfield, "Venlafaxine. A Review of Its Pharmacology and Therapeutic Potential in Depression,” Drugs, Vol. 49, No. 2, 1995, pp. 280-294. doi:10.2165/00003495-199549020-00010

[2] C. Howell, A. D. Wilson and W. S. Waring, "Cardiovascular Toxicity Due to Venlafaxine Poisoning in Adults: A Review of 235 Consecutive Cases,” British Journal of Clinical Pharmacology, Vol. 64, No. 2, 2007, pp. 192197. doi:10.2165/00003495-199549020-00010

[3] K. Hawton, H. Bergen, et al., "Toxicity of Antidepressants: Rates of Suicide Relative to Prescribing and NonFatal Overdose,” British Journal of Psychiatry, Vol. 196, No. 5, 2010, pp. 354-358. doi:10.1192/bjp.bp.109.070219

[4] C. A. Kelly, N. Dhaun, et al., "Comparative Toxicity of Citalopram and the Newer Antidepressants after Overdose,” Clinical Toxicology, Vol. 42, No. 1, 2004, pp. 6771. doi:10.1081/CLT-120028747

[5] D. Blythe and L. P. Hackett, "Cardiovascular and Neurological Toxicity of Venlafaxine,” Human \& Experimental Toxicology, Vol. 18, No. 5, 1999, pp. 309-313. doi:10.1191/096032799678840165

[6] I. M. Whyte, A. H. Dawson and N. A. Buckley, "Relative Toxicity of Venlafaxine and Selective Serotonin Reuptake Inhibitors in Overdose Compared to Tricyclic Antidepressant," QJM: An International Journal of Medicine, Vol. 96, No. 5, 2003, pp. 369-374. doi:10.1093/qjmed/hcg062

[7] T. Launiainen, I. Rasanen, E. Vuori and I. Ojanperä, "Fa- 
tal Venlafaxine Poisonings are Associated with a High Prevalence of Drug Interactions,” International Journal of Legal Medicine, Vol. 125, No. 3, 2011, pp. 349-358. doi:10.1007/s00414-010-0461-5

[8] B. Levine, A. J. Jenkins, M. Queen, R. Jufer and J. E. Smialek, "Distribution of Venlafaxine in Three Postmortem Cases,” Journal of Analytical Toxicology, Vol. 20, No. 6, 1996, pp. 502-505.

[9] A. T. Parsons, R. M. Anthony and J. E. Meeker, "Two Fatal Cases of Venlafaxine Poisoning," Journal of Analytical Toxicology, Vol. 20, No. 4, 1996, pp. 266-268.

[10] R. D. Budd and D. T. Anderson, "Postmortem Tissue Distribution of Venlafaxine: Six Case Studies,” Journal of Analytical Toxicology, Vol. 21, No. 1, 1997, p. 93.

[11] C. Long, J. Crifasi, D. Maginn, M. Graham and S. Teas, "Comparison of Analytical Methods in the Determination of Two Venlafaxine Fatalities," Journal of Analytical Toxicology, Vol. 21, No. 2, 1997, pp. 166-169.

[12] P. D. Jaff, H. P. Batziris, P. van der Hoeven, D. DeSilva and I. M. McIntyre, “A Study Involving Venlafaxine Overdoses: Comparison of Fatal and Therapeutic Concentrations in Postmortem Specimens," Journal of Forensic Sciences, Vol. 44, No. 1, 1999, pp. 193-196.

[13] K. E. Goeringer, I. M. McIntyre and O. H. Drummer, "Postmortem Tissue Concentrations of Venlafaxine," Forensic Science International, Vol. 121, No. 1-2, 2001, pp. 70-75. doi:10.1016/S0379-0738(01)00455-8

[14] A. Fantaskey and K. K. Burkhart, "A Case Report of Venlafaxine Toxicity,” Clinical Toxicology, Vol. 33, No. 4, 1995, pp. 359-361. doi:10.3109/15563659509028923

[15] L. Kokan and R. C. Dart, "Life-Threatening Hypotension from Venlafaxine Overdose,” Annals of Emergenca Medicine, Vol. 27, No. 6, 1996, p. 815.

[16] C. Hiemke, P. Baumann, et al., “AGNP Consensus Guidelines for Therapeutic Drug Monitoring in Psychiatry: Update 2011,” Pharmacopsychiatry, Vol. 44, No. 6, 2011, pp. 195-235. doi:10.1055/s-0031-1286287 